\title{
Modern Educational Domain: Bilingualism and Multilingualism in Teaching Foreign Languages
}

\author{
Natalia Rezepova ${ }^{1} \mathrm{PhD}$; Liya Torosyan ${ }^{2} \mathrm{PhD}$ \\ Katerina Stepanenko ${ }^{3} \mathrm{PhD}$; Farid Guseynov ${ }^{4} \mathrm{PhD}$ \\ Plekhanov Russian University of Economics, Russia

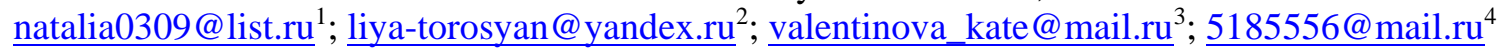

\begin{abstract}
Russian academic society has traditionally been considered linguistically and culturally homogeneous. However, during the last two decades there was observed a notable shift towards heterogeneous zooming in teaching field due to specific social, demographic and political changes. The topicality of the research is stipulated by linguistic and cultural fusion due to increasing number of people speaking two or more languages globally. The research goal is to prove that a teacher being natural bilingual and multilingual can be far more effective and impactful in the educational process than an artificial bilingual and multilingual one. To envision possible prospects and benefits of natural bilingual and multilingual teachers within modern educational domain a special study was conducted. The research involved two pools of the participants: the students (220 students in general) and the teaching staff (26 teachers) at Plekhanov Russian University of Economics. After each experiment session all participants were encouraged to fill in Self-Reported Questionnaire (SRQ) and to pass Free association test (FAT). Both of the monitoring instruments are implemented to verify each other to reveal and assess students' attitude to the teachers' input into "enrichment" of the educational process and consecutive boost in students' linguistic and metalinguistic abilities. The authors put forward hypotheses suggesting there is a link between students' assertiveness to be more involved in foreign languages learning process with natural bilingual and multilingual teachers and such interaction within cultural linguistic framework may be appealing to all students. The results obtained through SRQ and FAT demonstrated the impressive rise of students' engagement into the educational process and significant boost in motivation after the second session of the experiment. The aforesaid witnesses that such vector shift in the learning process is seen in its overall introduction into the academic setting in order to upgrade modern educational environment and specifically in teaching foreign languages.
\end{abstract}

Keywords: modern educational domain, bilingualism, multilingualism, university education.

\section{Introduction}

It has been noted that social mobility is on the steady rise in the modern global world in the second half of the twentieth century and at the beginning of the twenty first century. The underlying causes for this phenomenon are historical, economic, political and social ones. Wars, significant political upheavals like the USSR collapse, new long-lasting military conflicts with a large number of refugees, rising unemployment rate and other social reasons forced people to flee in search of safety and better living standards. This leads to lingual and cultural interblending which in its turn initiates language specific, communication and integration issues which are highly relevant in present-day conditions. The result of all these processes is that increasing number of people can speak two or more different languages. Natural consequence of such tendency has become reinforcement of the phenomena of bilingualism and multilingualism.

The aim of the research is to prove that a teacher being natural bilingual and multilingual can be far more effective and impactful than an artificial bilingual and multilingual one within a modern educational domain.

\section{Methodology}

The authors set a goal to demonstrate that multilingual teachers are more interactive and perceptive to students' needs and requirements, being able to demonstrate a set of specific features inevitably influencing a process of teaching foreign languages.

The research goal states its objectives to determine inherent constituents of those features, to assess their contribution to learning practices and academic achievements of the students, and to obtain students' feedback on distinguishing any differences between artificial bilingual and natural bilingual or 
multilingual teachers in ways of interaction, materials representation, and influence on their motivation to actively participate in educational activities.

As modern university students tend to demonstrate self-centred positioning and claim to be able to access all subject-matter information, there is a vital need to interpose something brand new to get them interested. This very fact triggers an issue on a new interpretation of teacher's competencies that should meet diverse and excessive needs of the university youth fostering them to imply their background knowledge and skills in a beneficial way.

Consequently, the authors of the research paper put forward a hypothesis whether there is a link between students' assertiveness to be more involved in educational processes with natural bilingual or multilingual teachers than in those conducted by artificial bilingual or multilingual ones. They also hypothesized that interaction within cultural linguistic framework of natural bilingual and multilingual teachers may be appealing to all the students independently from them being monolinguals, bilinguals or multilinguals, as these teachers tend to demonstrate "switchover" abilities, flexibility and sensitivity to cultural and linguistic diversity of the students.

Participants. The research involved two pools of the participants. The firs pool was represented by the students (220 students in general: 118 first year students and 102 third year students at C1 English level at Plekhanov Russian University of Economics). The second pool was represented by the teaching staff (26 teachers) of Chair of Foreign Languages \#2 at Plekhanov Russian University of Economics.

The students' pool characteristics: 126 students identified themselves as being artificial bilinguals (with consecutive acquisition of a foreign language), 73 students identified themselves as being natural bilinguals but artificial multilinguals (with simultaneous acquisition of first two languages and consecutive acquisition of a foreign language), and 21 students identified themselves as being natural multilinguals (with simultaneous acquisition of first three languages and consecutive acquisition of a foreign language). The teachers' pool characteristics: 13 teachers identified themselves as being artificial bilinguals or multilinguals (with consecutive acquisition of a foreign language), 10 teachers identified themselves as being natural bilinguals but artificial multilinguals (with simultaneous acquisition of first two languages and consecutive acquisition of a foreign language), and 3 teachers identified themselves as being natural multilinguals but artificial multilinguals (with simultaneous acquisition of first three languages and consecutive acquisition of a foreign language).

The participants were informed about the purpose of the research and voluntarily participated in it.

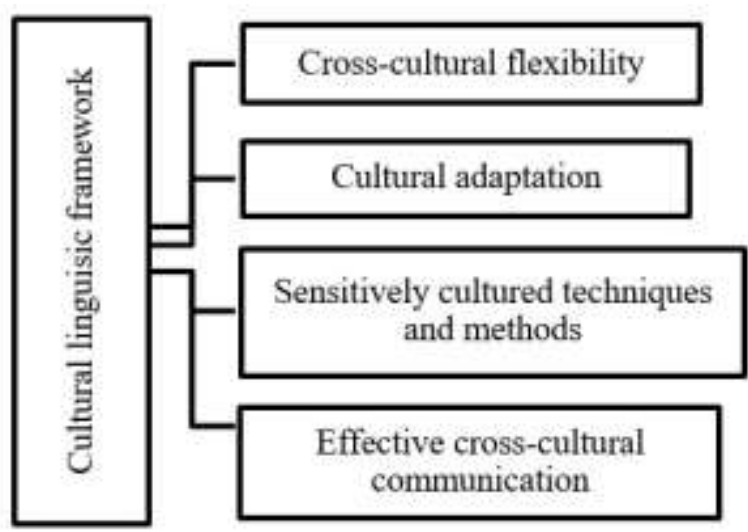

Figure1. Cultural linguistic framework (specific factors in teaching foreign language).

Methods. The authors of the paper suppose that the methods of the research should be selected considering a cultural-linguistic framework incorporating the four indispensable components. This framework is believed to be applicable to show dissimilarity among teachers with various linguistic characteristics, as it is aimed at the criteria that do not reflect literacy and language proficiency as teacher's professional competencies but highlight complex extra linguistic phenomena. These are represented in Figure 1.

Self-Reported Questionnaire (SRQ) was used to assess students' attitude to the teachers' input into "enrichment" of the educational process and consecutive boost in students' linguistic and metalinguistic abilities. In order to validate SRQ results concept analysis through Free association test was applied. 
The concept as a basic cultural cell in a person's mentality focuses on the meaning of a sign. It is reflected in person's comprehension, ideas and implications about the images of the world at a linguistic and cognitive level. It shows basis that the person imports into a concept and indicates the level of its perception culturally and linguistically.

The concept is a multilevel mental structure which includes sound cover of the word, supposition, comprehension, adaptation, evaluations, relations (Pishchalnikova, Rogozina, 2004). Thus, the interrelationship and their possible modulation at the functional and dynamic level between the concept's steady components manifest the appearance of a new content concept.

Procedure. The research was divided in two sessions. The first session lasted 4 months (first term due to the University curriculum). The students' pool of participants was explained that their English classes would be conducted by the 13 teachers who are artificial bilinguals or multilinguals (with consecutive acquisition of a foreign language). They were informed that their feedback would be collected through SRQ and word association responses after the first session and after the second one. The students were provided with all the necessary instructions.

Self-Reported Questionnaire was structured in a way to verify the authors' hypothesis on the distinction of potential input by the teachers with different linguistic characteristics in the effectiveness of educational process and students' academic achievements. So, it incorporated the two blocks: the first was aimed at measuring common teacher's competencies while the second - at measuring students' sensitivity to teacher's cultural and linguistic characteristics:

- Was the teacher articulate and coherent in representing new materials?

- Did the teacher's assignments appropriately meet challenging students' expectations?

- Was the teacher good at selecting and adapting resources in a learning process?

- Did the teacher manage to master lesson content in accordance with students' expectations?

- Was the teacher able to take advantage of cultural and personal experiences and resources?

- Was the teacher proficient in "bridging languages" while making implications in case of being asked to exemplify some phenomena in different languages?

- Did the teacher manage to demonstrate divergent and creative thinking via sensitively cultured techniques and methods?

- Did the teacher run classes in the conditions of cross-cultural communication environment effectively?

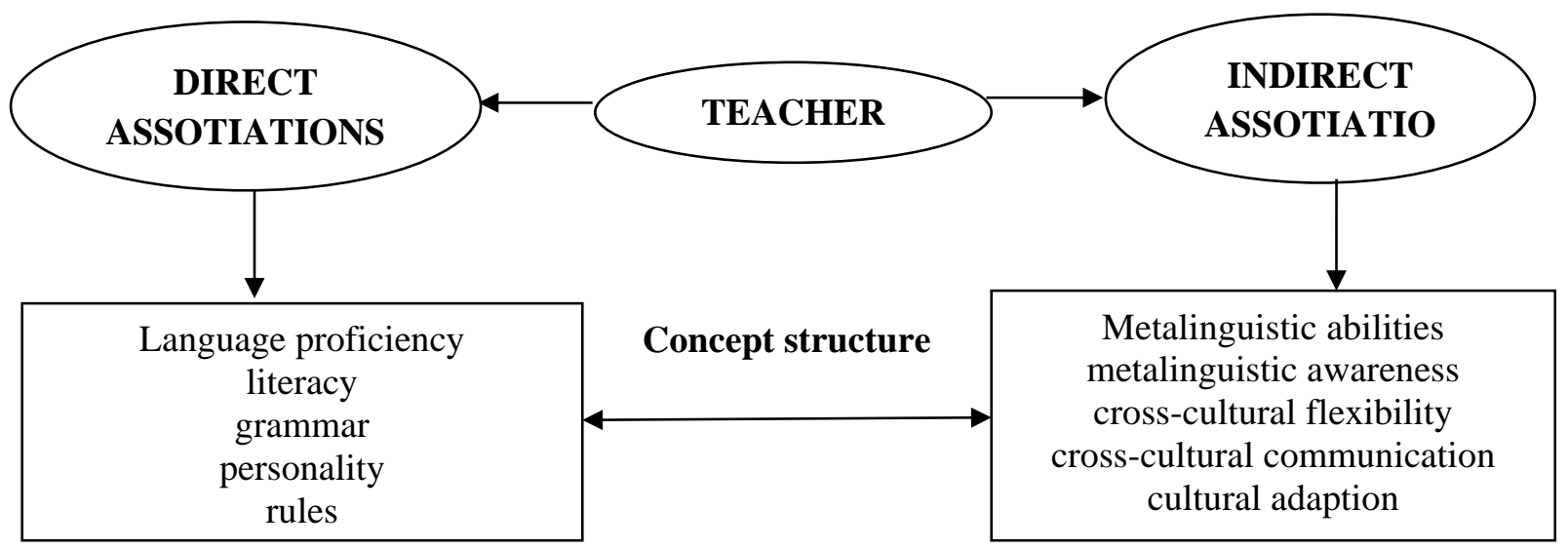

Figure 2. The model of Free association test.

The FAT incorporated 10 words (Figure 2). Five of them were designed as direct associations to specify the students' views and understanding of the concept "teacher" related to common teacher's competencies. The other five words and word combinations were used as indirect associations to reveal students' attitude to the cultural-linguistic framework of a teacher as a subcompetency. Tests were handed out to the students' pool of participants together with a request to fix next to stimulus word or word combination the first association which springs to their mind. Each student identified their linguistic characteristics on the test. 
The second session lasted 5 months (second term due to the University curriculum). The students' pool of participants was explained that their English classes would be conducted by the 13 teachers who are natural bilinguals but artificial multilinguals (with simultaneous acquisition of first two languages and consecutive acquisition of a foreign language), and natural multilinguals (with simultaneous acquisition of first three languages and consecutive acquisition of a foreign language), artificial bilinguals or multilinguals (with consecutive acquisition of a foreign language).

After the second session, the same SRQ form and FAT were again submitted to the students. The sessions were based on the course book Market Leader Intermediate $3^{\text {rd }}$ Edition Extra that consists of 12 units. Each unit has 5 sections: discussion, texts, language work, skills, and case study. Moreover, there are four additional chapters on working across cultures. In reading section students were able to acquaint themselves with authentic articles on a variety of business issues. Except for developing reading skills and perceiving essential business vocabulary students discussed ideas highlighted and detailed in the articles. Listening section is aimed at perfecting listening for information and note-taking. Language review section clarifies problematic fields at this level. Skills section focuses on developing vital business communication skills, and application of English in social situations. Case studies contain realistic business issues or scenarios which allowed students to use language and communication skills. The four additional chapters "Working across cultures" point out various aspects of international communication which helped students to raise their awareness of possible issues that may emerge while having business affairs with people of different cultural backgrounds.

The authors of the research suppose that this very content (considering its cultural diversity) can be considered as contributing to a foreign language teacher's cultural linguistic framework activation and corresponding responsive reaction from students.

\section{Results and discussion}

\section{Theoretical Background of Empirical Research}

Some scientists emphasized terminological problems with bilingualism and multilingualism. U. Weinreich (1953) considers bilingualism as a practice of turn-based language use. F. Grosjean (1992; 2010) describes bilingualism as a regular use of two and more languages. V. Vildomec (1963) clarifies that bilingualism is a mastery of two languages whereas multilingualism is a command of more than two languages. According to some scholars, bilingualism is considered as «a variant of multilingualism» (Herdina, Jessner, 2002, 52). In this article the authors refer to bilingualism as knowledge/use of two languages, and multilingualism - as more than two languages.

A wide range of classifications of bilingualism and multilingualism exist. Bilingualism and multilingualism can be divided into state and individual. C. Baker makes a distinction between «bilingualism as an individual characteristic and bilingualism in a social group, community, region or country» termed «individual bilingualism and societal bilingualism» (Baker, 2001,2). In the USSR with population 250 million people fourteen out of fifteen former republics represented a situation with a state bilingualism. Such countries as Canada and India exemplify a state bilingualism. Switzerland and Belgium are bright examples of a state multilingualism. Modern Russia with 150 million people population is a multinational country with a high proportion of bilinguals and multilinguals. As for an individual bilingualism, it shouldn't be left unmentioned a famous Russian and English writer V. Nabokov. Speculating on his bilingualism he compared the command of his English and Russian saying that his Russian was far looser than English, and the difference between them was the same as between a semi-detached house and a mansion (Nabokov, 1981). It is considered that a person is practically unable to master two and more languages identically well: one of the languages they speak, or use is dominant, or at least it's a very rare phenomenon called a balanced bilingualism which implicates an «equal and strong competence» in two languages (Baker, 2001, 29). This thesis is illustrated by the abovementioned example with V. Nabokov.

Analysing the phenomenon of bilingualism and multilingualism it is worth mentioning artificial and natural types. The natural type occurs in a relevant linguistic environment (in a natural context), which means that a language is acquired «without any special tuition» (Saunders, 1990, 115). The artificial one implies mastering of a second, third or next language in a teaching or academic environment (Hansen, 2008). 
W.E. Lambert $(1974 ; 1977)$ identified two types of bilingualism: additive and subtractive. Additive bilingualism means that a second foreign language does not drive out the first. The subtractive type indicates that a second language substitutes the first. This type might be exemplified by bilingual immigrants who no longer use their first language actively but still understand it.

There could be differentiated an active and passive types of bilingualism. The former type actively communicates in both languages, while the latter - in only one of them. C. Baker (Baker, 2001, 18) gives the following description to passive bilinguals: «Some listen with understanding and read a language but do not speak or write that language. Some understand a spoken language but do not themselves speak that language». For instance, providing a person both understands and speaks Russian and English, he is considered to be an active bilingual. If a person understands both of the languages, but speaks only one of them, he is described as a passive one.

Some scientists implement different terms for bilinguals such as dual language learner (Paradis, Genesee, Crago, 2011) or L2 user (Cook, 2013). V. Cook (Cook, 2013, 46-49) argues that they cannot be simply described as monolinguals with additional knowledge, they differ from monolinguals in many ways, such as the following:

- L2 users think in slightly different ways from monolinguals;

- L2 users use language in different ways from monolinguals;

- L2 users have an increased awareness of language itself compared to monolingual;

- L2 users have a slightly different knowledge of their first language;

- L2 users have different brain structures from monolinguals.

C. Baker (2001) claims that knowledge of two languages inevitably encourages to reflect upon a language itself, its functions, to focus on common features of both languages, to be conscious of your native language and to perceive it as a subject of speculation but not as a means of expressing thoughts. This leads to a "special awareness" in linguistic operations.

According to numerous researchers (Bialystok, 1991; Bialystok, 2001; Bruck, Genesee, 1995; Chen et al., 2004; Cummins, 1978; Galambos, Goldin-Meadow, 1990; Yelland, Pollard, Mercuri, 1993), bilingualism and multilingualism improves metalinguistic abilities of a person. Metalinguistic awareness contributes to teachers' universal and cultural literacy and expertise, enriches background knowledge and enhances professional competence. In case of bilingualism and multilingualism a teacher masters two and more languages, applies his knowledge and skills immediately in the classroom and transmit them to students. Thus, bilingualism or multilingualism provides more conscious attitude to a language developing metalinguistic and cultural awareness.

Generally, while studying a second foreign language an authentic communication does not take place in the classroom being simulated artificially to a greater or lesser degree of success. The authors are assured that metalinguistic and cultural awareness which is evidently a result of being bilingual or multilingual puts down to teachers' efficiency in a classroom environment. In this work the authors have made an attempt to measure teachers' effectiveness in the classroom comparing natural and artificial bilinguals and multilinguals among teaching staff members of foreign languages chair\#2 at Plekhanov Russian University of Economics. The aim of this study is to focus on teaching staff individual natural and artificial bilingualism and multilingualism as applied to criteria of efficiency in the classroom and boosting motivation among students.

A traditional teacher is an authentic linguistic personality possessing conditioned mentality of one culture, a specific one-angled picture of the world and the system values, adhering to certain cognitive approaches, behavioural and communicative norms (monolinguals). Providing a teacher is a natural bilingual and multilingual, his profile has been transformed into an educator with secondary or even tertiary linguistic personalities whose linguistic picture of the world as a part of the conceptual whole easily switches from one layer to another. Moreover, natural bilingual and multilingual teachers can be considered unique and irreplaceable from professional point of view as they are able to exist in two and more conceptual dimensions where the perception of one culture is not filtered and distorted by another culture or experience, traditions and values as these layers cohabit independently in their consciousness. Their natural cultural competence as an ability to function effectively in multicultural settings allows them to become active reflective mediators 
and to establish strong academic and social networks of a wide variety. Main elements as competitive advantages of this new type of educators are as follows (Figure 3):

- multilevel presupposition implies preliminary or background knowledge which embrace general knowledge about surrounding community, narrow-format knowledge (some specific knowledge which is relevant to the given situation), and linguistic knowledge;

- cross-cultural flexibility is a teacher's ability to orientate in a new cultural environment, to facilitate a teacher-student or student-student communication by easily adapting to a different culture;

- diversification of values, beliefs, norms and standards is a strategy applied by a teacher to selectively use those values, beliefs, norms and standards which are appropriate for the given communicative situation.

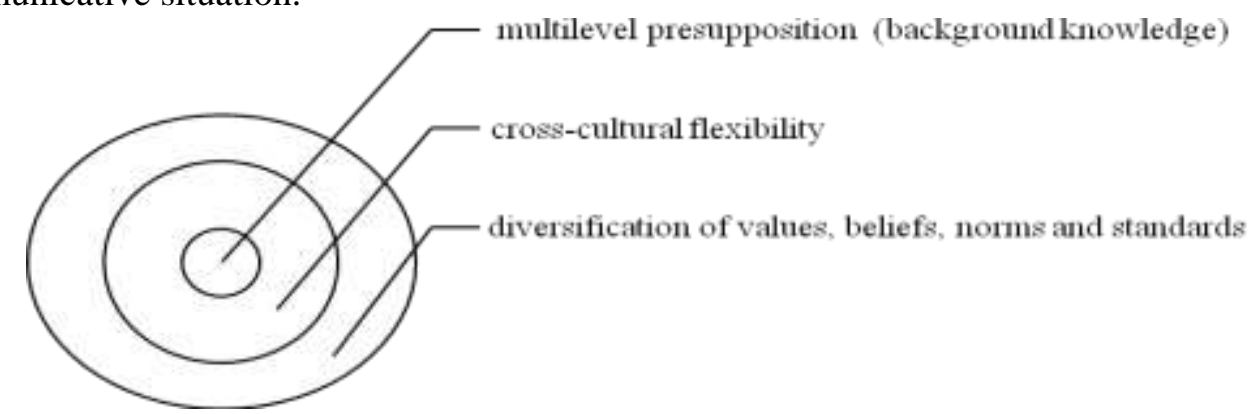

Figure 3. The competitive advantages of bilingual and multilingual teaching staff.

These above listed elements as competitive advantages of bilingual and multilingual teachers have already been recognized and appreciated by academic environment which is promoting metalinguistic and cultural competencies within the university community.

\section{Results of Empirical Research}

The SRQ allowed revealing some shifts in the distinction of potential input by the teachers with different linguistic characteristics in the effectiveness of educational process and students' academic achievements. Thus, it is noteworthy that the fist block of questions incorporated in the SRQ demonstrated almost the same gradual paradigm from being assertive to being neutral, and finally to being negative (Figure 4; Figure 5):

1. Was the teacher articulate and coherent in representing new materials?

2. Did the teacher's assignments appropriately meet challenging students' expectations?

3. Was the teacher good at selecting and adapting resources in a learning process?

4. Did the teacher manage to master lesson content in accordance with students' expectations?
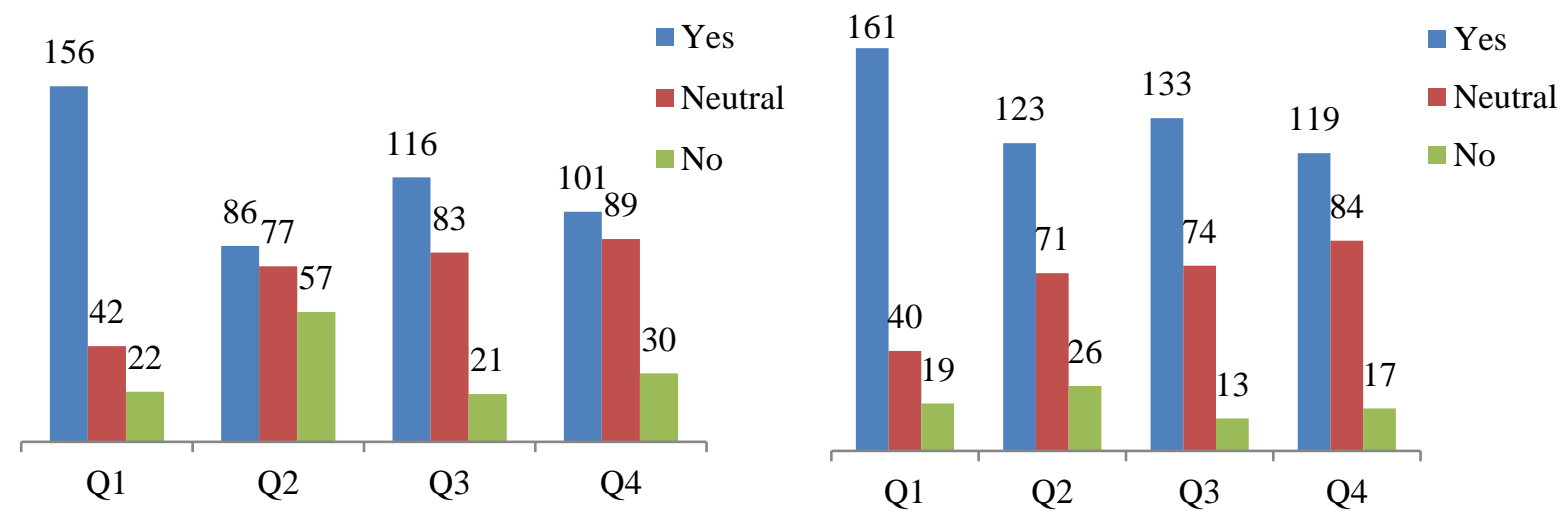

Figure 4. First session SRQ Results (Block 1).

Figure 5. Second session SRQ Results (Block 1).

The response dispersion is not of a great significance, which causes to assume that the students have approximately the same perception of common teachers' competencies independently from them being artificial bilinguals, or natural bilinguals but artificial multilinguals, or natural multilinguals. 
Still there is a marked turnaround related to the second block of questions (Figure 6; Figure 7):

1. Was the teacher able to take advantage of cultural and personal experiences and resources?

2. Was the teacher proficient in "bridging languages" while making implications in case of being asked to exemplify some phenomena in different languages?

3. Did the teacher manage to demonstrate divergent and creative thinking via sensitively cultured techniques and methods?

4. Did the teacher run classes in the conditions of cross-cultural communication environment effectively?

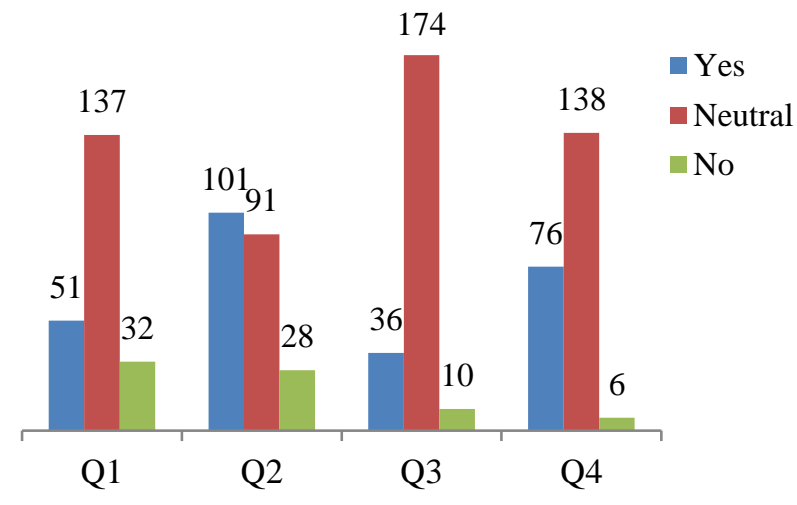

Figure 6. First session SRQ Results (Block 2).

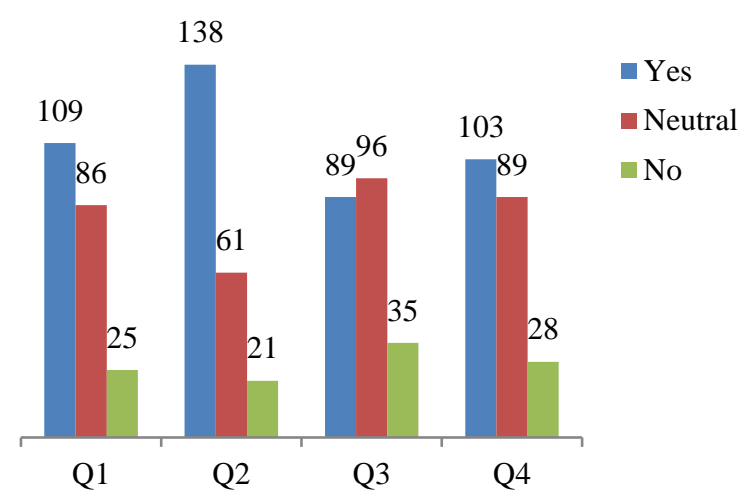

Figure 7. Second session SRQ Results (Block 2).

The first session of the research participants based on the second block of questions showed an excessively high rate of "neutral" answers ("I actually do not quite catch it", "It is hard to assess it for sure"). After being requested to clarify these indicators the students expressed a statement that may generally denote their vague and blurry perception of cultural and linguistic characteristics of artificial bilingual teachers due to a specific type of interaction. This type of interaction can be identified as initiate-respond-evaluate (I-R-E) chain that used to be a patterned sample for teacher-student's cooperation. Hence, that scheme of interaction deprived the students a chance to assess teachers' background cultural and linguistic characteristics.

Conversely, the second session SRQ results demonstrated far more distinct and improved indicators of teacher's background cultural and linguistic characteristics. All the indicators (except for Q3 criteria) are in degressive gradation from being assertive to being neutral, and to being negative which undoubtedly signal about distinguishing evident differences between artificial bilingual and natural bilingual or multilingual teachers in ways of interaction, materials representation, and influence on students' motivation to actively participate in educational activities. The results of the second session also show higher degree of students' engagement in the learning process which consequently increases their attention and focus on the subject and motivates to apply higher-level critical thinking.

To recheck the findings the FAT (Free Association Test) was brought into use. The results illustrate the ratio of the concept "teacher" elements received through the FAT (Figure 8; Figure 9). According to the derived data after the first session there were obtained most common associations:- notions: knowledge, education, language, facts, understanding, information, explanation, analysis (32\% of the total amount of the associations); - conceptions: book, classroom, master, perfect, practice, exercise, results, feedback, basis (52\%); -estimations and emotions: informative, supportive, motivating, correcting, disciplined, responsive $(25 \%)$.

After the second session the results distributed as is: - notions: ability, knowledge, culture, flexibility, education, facts, understanding, information, explanation, analysis ( $32 \%)$; - conceptions: think, discuss, realize, adaptability, exercise, results, behaviour, feedback, strategy (52\%);- emotions and estimations: science, develop, informative, responsive, interactive, motivating, inspiring $(25 \%)$.

Analysis of the results witnesses alterations of the concept structure among the research participants: while the first representation shows predominance of associations that were initially generalized as direct ones (language proficiency, literacy, grammar, personality, rules), the second representation demonstrates a shift to indirect ones (metalinguistic abilities, metalinguistic awareness, cross-cultural flexibility, cross-cultural communication, cultural adaption). 
"Teacher" concept structure (First session)

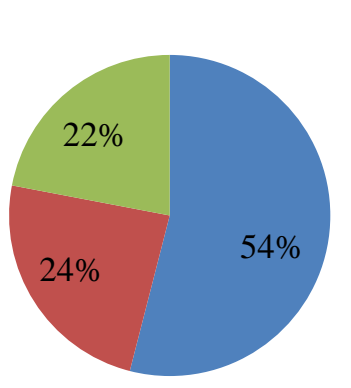

"Teacher" concept structure (Second session)

- Notions

- Conceptions

$\square$ Emotions and

Estimations

Figure 8. "Teacher" concept structure (1).

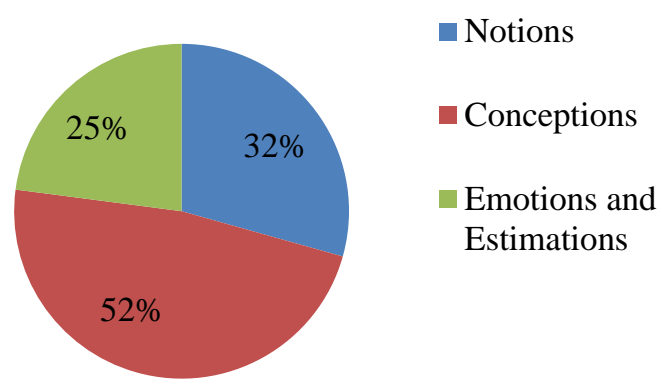

Figure 9. "Teacher" concept structure (2).

The validated change of vector is stipulated by such critical factors as higher degree of students' involvement into the learning process, closer interaction "student-teacher-class" and adaptation/tolerance towards multicultural environment. Obvious benefits of this scenario would be cultural consciousness strengthening, amplification of intercultural awareness, multiple historical perspectives, encouraged critical thinking, prevented stereotypes and prejudicial behaviour.

\section{Conclusion}

Russian modern educational domain has been developing divergently linguistically and culturally due to be a multinational country with a major share of bilinguals and multilinguals. This fact led to considering teaching foreign languages process multifacetedly as applied to natural and artificial bilingual and multilingual teaching staff. The research was conducted to prove that natural bilingual or multilingual teachers possessing "switchover" abilities, being cross-culturally flexible and adaptive to diverse educational environment are far more effective and influential than artificial bilingual and multilingual ones.

The research indicated that the hypotheses were fully confirmed. Registered findings demonstrate students' awareness and willingness to be more engaged into the educational process in the format of joint research and learning activities with natural bilingual or multilingual teachers than in those conducted by artificial bilingual or multilingual ones.

Many participants really confirmed a change in concept structures towards indirect ones after the second session (with natural bilingual or multilingual teachers) noting development of metalinguistic abilities, strengthening of metalinguistic awareness, enhancement of cross-cultural flexibility, amplification of cross-cultural communication and tolerance.

Moreover, the participants showed a clear motivation to be involved into the educational process with natural bilingual and multilingual teacher who are able to apply various culture-centered sensitive teaching techniques and strategies thus ensuring adequate insight into students' perception, values, beliefs, and social interactions in multicultural classes. The demonstrated metalinguistic and cultural awareness of such educators which is evidently a result of being natural bilinguals or multilinguals assures their efficiency and uniqueness in a classroom and academic environment.

\section{Bibliography}

1. Baker C. (2001). Foundations of Bilingual Education and Bilingualism (3rd ed.). Clevedon: Multilingual Matters LTD. Retrieved from https://criancabilingue.files.wordpress.com/2013/10/colin-baker-foundations-of-bilingualeducation-and-bilingualism-bilingual-education-and-bilingualism-27-2001.pdf

2. Bialystok E. (2001). Metalinguistic Aspects of Bilingual Processing. Annual Review of Applied Linguistics, 21, 169-181.

3. Bialystok E. (Ed.) (1991). Language Processing in Bilingual Children. UK: Cambridge University Press. Retrieved from http://assets.cambridge.org/97805213/70219/sample/9780521370219ws.pdf 
4. Bruck M., Genesee F. (1995). Phonological Awareness in Young Second Language Learners. Journal of Child Language, 22(2), 307-324.

5. Chen X., Anderson R.C., Li W., Hao M., Wu X., Shu H. (2004). Phonological Awareness of Bilingual and Monolingual Chinese Children. Journal of Educational Psychology, 96(1), 142-151.

6. Cook V. (2013). What are the Goals of Language Teaching? Iranian Journal of Language Teaching Research, 1(1), 44-56. Retrieved from https://files.eric.ed.gov/fulltext/EJ1127428.pdf

7. Cummins J. (1978). Bilingualism and the Development of Metalinguistic Awareness. Journal of Cross-Cultural Psychology, 9(2), 131-149. Retrieved from https://numerons.files.wordpress.com/2012/04/07-bilingualism-and-the-development-ofmetalinguistic-awareness.pdf

8. Galambos S.J., Goldin-Meadow S. (1990). The Effects of Learning Two Languages on Levels of Metalinguistic Awareness. Cognition, 34 (1), 1-56.

9. Grosjean F. (1992). Another View of Bilingualism. In R. J. Harris (Ed.), Cognitive Processing in Bilinguals. Amsterdam: North-Holland, 51-62.

10. Grosjean F. (2010). Bilingual: Life and Reality. Cambridge, Mass: Harvard University Press.

11. Hansen K. (2008). Reflections on the Concept of Linguistic Situation. In H.G. Wolf, L. Peter, F. Polzenhagen (Eds.), Focus on English Linguistic Structure, Language Variation and Discursive Use. Leipzig: Leipziger Universitatsverlag GmbH, 19-49.

12. Herdina P., Jessner U. (2002). A Dynamic Model of Multilingualism: Perspectives of Change in Psycholinguistics. Clevedon: Multilingual Matters LTD.

13. Lambert W.E. (1974). Culture and Language as Factors in Learning and Education. In F.E. Aboud, R.D. Meade (Eds.), Cultural Factors in Learning and Education. Bellingham. WA: 5th Western Washington Symposium on Learning, 91-122.

14. Lambert W.E. (1977). The Effects of Bilingualism on the Individual: Cognitive and Socio-cultural Consequences. In P. Hornby (Ed.), Bilingualism. Psychological, Social and Educational Implications. New York: Academic Press, 15-27.

15. Nabokov V. (1981). Lectures on Russian Literature. New York: Harcourt Brace. Retrieved from https://archive.org/stream/VladimirNabokovLecturesOnRussianLiterature/Vladimir_Nabokov L ectures on Russian_LiteratureBookFi.org djvu.txt

16. Paradis J., Genesee F., Crago M.B. (2011). Dual Language Development and Disorders. A Handbook on Bilingualism and Second Language Learning (2nd ed.). Baltimore, London, Sydney: Paul H. Brooks Publishing Co.

17. Pishchalnikova V.A., Rogozina I.V. (2004). Koncept kak instrument diagnostiki ehtnicheskoj napryazhennosti (Concept as a Diagnostic Tool for Ethnic Tensions). Yazykovoe soznanie: teoreticheski i prikladnye aspekty. Barnaul: Izd-vo Altajskogo universiteta, 121-128. (In Russian)

18. Saunders G. (1990). Artificial bilingualism: Must it Fail? In M.A.K. Halliday, J. Gibbons, H. Nicholas (Eds.), Learning, Keeping and Using Language: Selected Papers from the Eighth World Congress of Applied Linguistics, 1. Amsterdam/Philadelphia: John Benjamins Publishing Company, 115-134.

19. Vildomec V. (1963). Multilingualism. Leyden: A.W. Sythoff.

20. Weinreich U. (1953). Languages in Contact: Findings and Problems. New York: Linguistic Circle of NewYork.

21. Yelland G.W., Pollard J., Mercuri A. (1993). The Metalinguistic Benefits of Limited Contact with a Second Language. Applied Psycholinguistics, 14(4), 423-444. 